\title{
CERVICAL SMEARS- STUDY DONE IN A TERTIARY CARE HOSPITAL
}

\author{
Letha Padmom¹, Devi Beena², Kiran Sapru ${ }^{3}$
}

${ }_{1}^{1}$ Associate Professor, Department of Pathology, Azeezia Institute of Medical Sciences and Research, Kollam, Kerala, India. ${ }^{2}$ Assistant Professor, Department of Pathology, Azeezia Institute of Medical Sciences and Research, Kollam, Kerala, India. ${ }_{3}^{3}$ Assistant Professor, Department of Pathology, Azeezia Institute of Medical Sciences and Research, Kollam, Kerala, India.

\section{ABSTRACT}

\section{BACKGROUND}

Cancer of cervix is the third most common cancer in women and an important cause for mortality. This can be identified at preinvasive stage with the help of PAP smear screening program. We wanted to evaluate the use of PAP smear as a screening method for detecting precancerous lesions using Bethesda system 2016.

\section{MATERIALS AND METHODS}

This retrospective study included 970 women who came to our OBG department during the period January 2016 - December 2018. Gynaecological examination and PAP smear screening was done and was reported using Bethesda 2016.

\section{RESULTS}

A total of 970 PAP smears were examined of which $33.4 \%$ turned to be normal. $56.7 \%$ were of infectious and inflammatory aetiology and epithelial abnormalities were seen in $2.78 \% .5 .15 \%$ were inadequate samples.

\section{CONCLUSION}

PAP smear is a simple, non-invasive, cheap and effective test which has drastically brought down the incidence of cancer of cervix as it is detected and treated at an earlier stage.

\section{KEY WORDS}

Cervical Cytology, PAP Smear, Bethesda System

HOW TO CITE THIS ARTICLE: Padmom L, Beena D, Sapru K. Cervical smears- study done in a tertiary care hospital. J. Evolution Med. Dent. Sci. 2019;8(12):859-862, DOI: 10.14260/jemds/2019/191

\section{BACKGROUND}

Cervical cancer is a major global health problem ${ }^{[1]}$ and incidence is about $8.3 \%$ in developing countries and $3.6 \%$ in developed countries.[2] According to world cancer statistics the incidence of cervical carcinoma is mainly due to unawareness and difficulty in running cytology based screening program.[3] India has developed various cervical screening programs and it has shown striking reduction in mortality from cervical cancer. ${ }^{[4]}$ Cervical cancer is an easily preventable disease mainly due to long preinvasive stage. If robust screening is implemented, early detection and appropriate treatments are possible. By a PAP smear test early cervical epithelial changes can be identified, which is a primary screening test for detection of precancerous lesions in cervix and early stage of invasive cervical cancer. Pap smear positive women need adequate treatment and regular follow up. By early detection and appropriate intervention towards the precursor lesion by a simple pap smear test cervical cancer is readily preventable. The overall sensitivity of high grade squamous intraepithelial lesion (HSIL) detection by doing a pap test is $70-80 \% .{ }^{[5]}$

'Financial or Other Competing Interest': None.

Submission 01-02-2019, Peer Review 08-03-2019,

Acceptance 14-03-2019, Published 25-03-2019.

Corresponding Author:

Devi Beena,

Assistant Professor

Department of Pathology,

Azeezia Institute of Medical Sciences and Research

Kollam, Meeyannoor, Kerala, India.

E-mail: devibeena1987@gmail.com

DOI: $10.14260 /$ jemds/2019/191
Different guidelines about cervical screening are present. American College of Obstetricians and Gynecologists (ACOG) states all women of age 21 and above should be screened and it should be regardless of the age at commencement of sexual activity. A woman aged less than 21 years should not be screened despite of age at sexual exposure and other demeanour-allied risk factors. Accordingly, it is recommended that females who are having sexual exposure should undergo regular Pap smear testing. In many of the countries Pap smear screening is a routine process. Guidelines on frequency of testing may change from every three to five years. In case of aberrant results, on the basis of the nature of the aberrance, the test has to be redone in six to twelve months.

The cervicovaginal smear can yield many useful information. The main advantages are easy to obtain, can be assessed rapidly, and relatively economical. The maturation degree of the squamous epithelium of the female genital tract hinges largely on steroid hormones, usually oestrogen. In various studies by Press et al in 1986 and Kupryjanczyk and Moller in 1988 they stated that oestrogen receptors are in the squamous epithelium of the uterine cervix and vagina, chiefly in the basal cells and are revealed more greatly during the proliferative phase when compared to the secretory phase of the cell cycle, being responsible for the alterations in epithelial maturation. Thus, the significant relationship of squamous cells of varying maturation degree of cervical or vaginal smear may indicate the hormonal status of the female. The analysis of sex chromatin bodies like Barr bodies in the same smears may supply beneficial data in cases of congenital abnormalities. 


\section{Aim of The Study}

To evaluate the use of Pap smear as a screening method for detecting precancerous lesions using Bethesda system 2016

\section{MATERIALS AND METHODS}

A retrospective study was done on 970 patients who attended the OBG department during Jan 2016 - Dec 2018 (3 years) in a tertiary care hospital. All patients who had undergone pap smear testing during this period were included in this study. A sample was taken using Ayer's spatula and three smears were prepared for each case. Two smears were fixed by $95 \%$ ethanol and stained using Pap stains. The remaining smear was airdried and later stained by MGG stain. Repeat smears were taken only for suspicious cases and not for unsatisfactory samples.

Bethesda System has made a proposal that each Pap smear report should begin with an adequacy statement, which was one of the major advantages. In 1988, three major categories had been proposed by the Bethesda System for specimen adequacy, which are "satisfactory," "less than optimal" and "unsatisfactory." The 2001 Bethesda criteria for adequacy were customized to both conventional preparations and liquid-based preparations and was based on published data. In 2016 edition of the TBS atlas, data and clinical experience concerning adequacy of specimen since 2001 were evaluated broadly and lead to the benefaction of additional instructions for special situations, such as analysing cellularity in smears whose had undergone radiation, intervening substances and testing human papillomavirus.

A normal Pap smear report should preferably begin with a specimen adequacy statement, followed by whether "negative for intraepithelial lesion or malignancy" (NILM) or not. Auxiliary findings like reactive changes, infectious organisms are listed succeeding. About $91 \%$ of Pap tests are elucidated as such. Normal Pap smear tests, other than those cases which may show reactive changes or reparative changes, can be concluded by a cytotechnologist and need not be always analysed by a pathologist.

These cases were reported on the basis of the new Bethesda system for reporting cervical cytology 2016 which includes the following:

\section{Specimen Type}

Indicate conventional smear (Pap smear) vs. liquid-based preparation vs. other

\section{Specimen Adequacy}

- Satisfactory for evaluation (Describe Presence or Absence of Endocervical/Transformation Zone Component and any other Quality Indicators, e.g., Partially Obscuring Blood, Inflammation, etc.)

- Unsatisfactory for evaluation... (Specify Reason)

- $\quad$ Specimen rejected/not processed (Specify Reason)

- Specimen processed and examined, but unsatisfactory for evaluation of epithelial abnormality because of (Specify Reason)

\section{General Categorization (Optional)}

- Negative for Intraepithelial Lesion or Malignancy

- Other: See Interpretation/Result (e.g., endometrial cells in a woman $\geq 45$ years of age)
- Epithelial Cell Abnormality: See Interpretation/Result (Specify 'squamous' or 'glandular' as appropriate)

\section{Interpretation/Result}

Negative for Intraepithelial lesion or Malignancy

(When there is no cellular evidence of neoplasia, state this in the General categorization above and/or in the Interpretation/Result section of the report- whether or not there are organisms or other non-neoplastic findings).

\section{Non-Neoplastic Findings (Optional to Report Optional to} Report; List Not Inclusive)

\section{- $\quad$ Non-Neoplastic Cellular Variations}

- Squamous metaplasia.

- Keratotic changes.

- Tubal metaplasia.

- Atrophy.

- Pregnancy-associated changes.

\section{- $\quad$ Reactive Cellular Changes Associated with} - Inflammation (Includes Typical Repair)

- Lymphocytic (Follicular) Cervicitis

- Radiation.

- Intrauterine contraceptive device (IUD).

\section{- Glandular Cells Status Post Hysterectomy}

\section{Organisms}

- Trichomonas vaginalis.

- Fungal organisms morphologically consistent with Candida spp.

- $\quad$ Shift in flora suggestive of bacterial vaginosis.

- Bacteria morphologically consistent with Actinomyces spp.

- Cellular changes consistent with herpes simplex virus.

- Cellular changes consistent with cytomegalovirus.

\section{Other}

Endometrial cells (In a woman $\geq 45$ years of age) (Specify if "negative for squamous intraepithelial lesion")

\section{Epithelial Cell Abnormalities}

\section{Squamous Cell}

- Atypical squamous cells

- Of undetermined significance (ASC-US).

- $\quad$ Cannot exclude HSIL (ASC-H).

- Low- Grade squamous intraepithelial lesion (LSIL) (Encompassing: HPV/mild dysplasia/CIN 1)

- High- Grade squamous intraepithelial lesion (HSIL) (Encompassing: moderate and severe dysplasia, CIS; CIN 2 and CIN 3)

- With features suspicious for invasion (If invasion is suspected )

- Squamous Cell Carcinoma

\section{Glandular Cell}

- Atypical

- Endocervical cells (NOS or specify in comments)

- Endometrial cells (NOS or specify in comments)

- Glandular cells (NOS or specify in comments) 
- Atypical

- Endocervical cells, favour neoplastic.

- Glandular cells, favour neoplastic.

\section{- Endocervical Adenocarcinoma in Situ}

- Adenocarcinoma

- Endocervical.

- Endometrial.

- Extrauterine

- $\quad$ Not otherwise specified (NOS).

\section{Other Malignant Neoplasms}

(Specify)

\section{RESULTS}

Of the 970 pap smears examined $33.4 \%$ turned to be normal. $59.6 \%$ were of infectious and inflammatory aetiology and epithelial abnormalities were seen in $2.78 \%$. $5.15 \%$ were inadequate samples. Of the abnormal cases 528 cases $(54.43 \%)$ were inflammatory smears and $51(5.2 \%)$ were of infectious aetiology. Among the infectious cases the most common was bacterial vaginosis which accounted for 24 cases followed by candida and HSV. (Table 1).

Epithelial cell abnormalities were of $2.78 \%$ which included 5 cases each of ASCUS and ASCH. It also included 4 cases of AGUS, 3 cases were of LSIL, 7 cases were of HSIL and 2 cases were of invasive squamous cell carcinoma and 1 case of adenocarcinoma cervix. (Table 2).

There were also 50 cases (5.15\%) belonging to unsatisfactory and inadequate samples.

\begin{tabular}{|c|c|c|}
\hline Pap Smear Findings & Number of Cases & $\%$ \\
\hline Inadequate & 50 & $5.15 \%$ \\
\hline NILM & 324 & $33.4 \%$ \\
\hline Inflammation & 528 & $54.4 \%$ \\
\hline Infectious Aetiology & 41 & $5.2 \%$ \\
\hline Epithelial Cell Abnormalities & 27 & $2.78 \%$ \\
\hline Total Number of Cases & 970 & \\
\hline
\end{tabular}

\begin{tabular}{|c|c|c|}
\hline & Number of Cases & Percentage \\
\hline ASCUS & 5 & $0.51 \%$ \\
\hline ASCH & 5 & $0.51 \%$ \\
\hline AGUS & 4 & $0.41 \%$ \\
\hline LSIL & 3 & $0.30 \%$ \\
\hline HSIL & 7 & $0.72 \%$ \\
\hline SCC & 2 & $0.20 \%$ \\
\hline Adenocarcinoma & 1 & $0.10 \%$ \\
\hline \multicolumn{2}{|c|}{ Table 2. Epithelial Cell Abnormalities } \\
\hline \multicolumn{2}{|c|}{ ASCUS - atypical squamous cells of undetermined } \\
significance, ASCH - atypical squamous cell cannot exclude \\
HSIL, AGUS - atypical glandular cell of undetermined \\
significance, LSIL - low grade squamous intraepithelial \\
lesion, HSIL - high grade squamous intraepithelial lesion, \\
SCC - squamous cell carcinoma \\
\hline
\end{tabular}




\section{Jemds.com}

similar to the studies done by Push Lata and Sunita who got $0.48 \%$ and $0.36 \%$ respectively $[6,9]$.

Our study thus emphasizes the significance of PAP smear testing to identify abnormalities in cervical cytology

\section{CONCLUSION}

PAP smear test is a simple, economical test and is an important screening test for early identification of premalignant and malignant lesions of cervix. The correlation of our study with other studies indicates the efficacy and usefulness of pap smear and Bethesda system across different populations and settings.

\section{REFERENCES}

[1] Sengul D, Altinay S, Oksuz H, et al. Population based cervical screening outcomes in Turkey over a period of approximately nine and half years with emphasis on results for women aged 30-34. Asian Pac J Cancer Prev 2014;15(5):2069-74.

[2] Parkin DM, Bray F, Ferlay J, et al. Global cancer statistics, 2002. CA Cancer J Clin 2005;55(2):74-108.

[3] Nayir T, Okyay AR, Nizlican E, et al. Cervical cancer screening in an early diagnostic and screening center in Mersin, Turkey. Asian Pac J Cancer Prev 2015;16(16):6909-12.

\section{Original Research Article}

[4] Saha D, Ghosh S, Nath S, et al. Utility of pap smear screening for prevention of cervical cancer - a three year study from rural Tripura- a northeastern state of India. Int J Med and Dent Sci 2017;6(2):1456-61.

[5] Cronje HS. Screening of cervical cancer in the developing world. Best Pract Res Clin Obstet Gynaecol 2005;19(4):517-29.

[6] Sachan PL, Singh M, Patel ML, et al. A study on cervical cancer screening using pap smear test and clinical correlation. Asian Pac J Oncol Nurs 2018;5(3):337-41.

[7] Mehmetoglu HC, Sadikoglu G, Ozcakir A, et al. Pap smear screening in primary health care setting: a study from Turkey. N Am J Med Sci 2010;2(10):46772.

[8] Verma A, Verma S, Vashisht S, et al. A study on cervical cancer screening in symptomatic women using Pap smear in a tertiary care hospital in rural area of Himachal Pradesh, India. Middle East Fertil Soc J 2017;22(1):39-42.

[9] Bamanikar SA, Baravkar DS, Chandanwale SS, et al. Study of cervical PAP smears in a tertiary hospital. Indian Medical Gazette 2014. 